Thorax 1982;37:902-905

\title{
The management of congenital aortic stenosis
}

\author{
JOHN M REID, ERIC N COLEMAN
}

From the University Department of Cardiology and Child Health, Royal Hospital for Sick Children, Glasgow

ABSTRACT The progress of 128 patients with congenital aortic stenosis has been followed from one to 28 (mean 14) years. Fifty-eight underwent cardiac catheterisation, and 46 (36\% of the total) required surgical treatment. Of these, 42 were under 20 years old. Additional cardiac lesions were noted in five. Infective endocarditis was encountered in four. The onset of symptoms or increasing evidence of left ventricular hypertrophy on the electrocardiogram were the principal indications for catheterisation. Two-dimensional echocardiography is now important in this context. There were four deaths in the $\mathbf{4 6}$ surgically treated patients; three of these were early and the fourth was a late death three years after operation due to a massive cerebral embolus complicating infective endocarditis. The 42 survivors of operation and the 82 unoperated patients have remained under long-term supervision. Further surgery was necessary in 12 of the 42 surgically treated patients - valve replacement in seven of them two to eight years after valvotomy, replacement of a calcified xenograft valve in three, and repeat operation in two because of recurrence of subvalvar obstruction. Aortic stenosis is not a benign condition in childhood and adolescence. Close supervision is necessary and when any deterioration is detected further investigation as a prelude to probable surgery is mandatory. This should not be embarked on lightly in childhood unless there are pressing indications, particularly in view of the serious disadvantages of valve replacement in childhood.

The management of congenital aortic stenosis throughout childhood and adolescence still presents many problems. Earlier studies suggested a favourable prognosis during early life ${ }^{1}{ }^{1}$ but this was not substantiated by later authors. The main difficulty is to decide when detailed investigation that will probably be followed by surgical intervention is required. Operation should not be delayed in severe cases, not only because of the risk of sudden death ${ }^{1-3}$ but because of the possible danger of permanent damage to the myocardium resulting from prolonged ischaemia. Equally, surgery should be avoided in early childhood unless there are clearcut indications. Valve replacement is not curative. The most promising prosthetic valve has not yet survived beyond 16 years.

Barratt-Boyes recently reviewed the natural history and assessment for operation in 218 patients with congenital aortic valvar stenosis. ${ }^{4}$ Our present review of 128 patients presenting in infancy, childhood, or early adult life includes those with valvar, subvalvar, or supravalvar obstruction.

Address for reprint requests: Dr JM Reid, Department of Cardiology, Western Infirmary, Glasgow G11 6NT.

\section{Patients and methods}

During 1953-1980 128 patients (91 male, 37 female) presented with congenital aortic stenosis. The ages at presentation are tabulated in table $1 ; 41$ presented in infancy. Additional cardiac lesions were present in five, two having coarctation of the aorta and three either an atrial septal defect, ventricular septal defect, or patent ductus arteriosus. In addition, one patient had Turner's syndrome. Symptoms were present in 14; eight experienced exertional dyspnoea, three had chest pain, and three had dyspnoea and chest pain.

All the patients underwent full clinical examination, chest $x$-ray examination, and electrocardiography when first seen, and subsequent visits were at yearly intervals or more frequently if necessary. The disease was classified as mild, moderate, or severe on the basis of electrocardiographic (ECG) evidence

Table 1 Age at presentation in the 128 patients

\begin{tabular}{lllll}
\hline Age $(y)$ & $<1$ & $1-5$ & $6-9$ & $10-19$ \\
\hline No of patients & 41 & 70 & 11 & 6 \\
\hline
\end{tabular}


of left ventricular hypertrophy (when the summation of $\mathrm{SV}_{1}$ and $\mathrm{RV}_{6}$ was over $3.5 \mathrm{mV}$ ). In our arbitrary classification of severity, mild stenosis was held to exist when the sum was in the range 3.5-4.9 ( $\mathrm{n}=$ 70), moderate stenosis when it was 5.0-6.9 $(n=$ 18), and severe stenosis when the sum was 7.0 or above $(n=40)$.

Cardiac catheterisation and angiocardiography were performed in $\mathbf{5 8}$ patients. The indications for these investigations were the onset of symptoms or evidence of increasing left ventricular hypertrophy on the electrocardiogram.

\section{Results}

Follow-up of the 128 patients has been continued for one to 28 (mean 14) years. Seventy patients remained well and symptom-free with no deterioration of the mild left ventricular hypertrophy already present on the electrocardiogram. Fifty-eight patients underwent cardiac catheterisation on the basis of the criteria referred to above. The peak systolic gradient across the left ventricular outflow tract ranged from 30 to $180 \mathrm{~mm} \mathrm{Hg}$. In 43 the site of obstruction was at valve level, in 13 it was subvalvar, and in two it was supravalvar.

Forty-six patients $(36 \%)$ had surgical treatment, the principal indication being a peak systolic gradient over $50 \mathrm{~mm} \mathrm{Hg}$ with or without symptoms. The youngest was one month old, the oldest 24 years (table 2). The average age at operation was 11.8 years; the mean age of those who had valvotomy was 10.4 years, compared with 20 years for the two who had surgical relief of supravalvar stenosis. Fifty-eight operations were performed, as a second procedure was necessary in 12 patients.

In $31(67 \%)$ of the 46 patients who underwent operation the obstruction was at valve level. Nineteen of these had comissurotomy initially, which in seven cases was followed by valve replacement two to eight years later. Primary valve replacement was performed in 12 patients, the youngest of whom was

Table 2 Age and site of obstruction at operation in 46 patients

\begin{tabular}{|c|c|c|c|c|c|}
\hline & \multicolumn{5}{|l|}{ Age } \\
\hline & $0-4$ & $5-9$ & $10-14$ & $15-19$ & $>20$ \\
\hline $\begin{array}{l}\text { Valvar } \\
\text { Valvotomy }\end{array}$ & 3 & 7 & 7 & 2 & 0 \\
\hline $\begin{array}{c}\text { Primary valve } \\
\text { replacement }\end{array}$ & 0 & 0 & 7 & 3 & 2 \\
\hline Subvalvar & 1 & 4 & 5 & 3 & 0 \\
\hline $\begin{array}{l}\text { Supravalvar } \\
\text { Total }\end{array}$ & $\begin{array}{l}0 \\
4\end{array}$ & $\begin{array}{r}0 \\
11\end{array}$ & $\begin{array}{r}1 \\
20\end{array}$ & $\begin{array}{l}\mathbf{0} \\
8\end{array}$ & $\frac{1}{3}$ \\
\hline
\end{tabular}

Table 3 Present age of 124 survivors

\begin{tabular}{lllllll}
\hline Age $(y)$ & $0-4$ & $5-9$ & $10-14$ & $15-19$ & $20-24$ & $>24$ \\
\hline No of survivors & 3 & 17 & 33 & 30 & 5 & 36 \\
\hline
\end{tabular}

12 years. Three of these required a second operation as the original porcine xenograft became heavily calcified. Thus 22 valves were used in 19 patients (10 Björk-Shiley, eight Starr-Edwards, and four porcine xenograft). There were three deaths, one after commissurotomy and two after valve replacement.

Subvalvar obstruction was present in 13 patients $(28 \%)$ and was relieved by excision of a subvalvar ring, but repeat operation was necessary in two after four years because the obstruction returned. The two patients $(5 \%)$ with supravalvar stenosis required a Dacron patch.

Infective endocarditis occurred in four patients, one of whom had undergone valve replacement three years previously. She died after sustaining a massive cerebral embolus. One patient has not had any surgery, but valve replacement was performed in the remaining two, one of whom (aged 15 years) had a heavily calcified valve with an aneurysm of an aortic sinus. The organism responsible was coagulase-positive Staphylococcus aureus in two patients, but was unknown in the other two.

Three patients underwent uneventful pregnancies with the delivery of healthy infants. None of these patients has had surgical treatment so far. The ages of the 124 surviving patients are shown in table 3 .

\section{Discussion}

It is important to know the natural history of congenital aortic stenosis before surgical intervention is advocated. Campbell postulated that the prognosis should be guarded in patients who had not had surgical treatment. ${ }^{2} \mathrm{He}$ studied 87 patients for three to 32 years, the period of review continuing until death (22) or valvotomy (27). In the first year of life he recorded a high death rate $(23 \%)$, dropping to $1 \%$ per annum up to 20 years and rising steadily thereafter. He estimated that $40 \%$ died before their 30th birthday. Forty-six (36\%) of our patients required surgery, 42 of whom were under 20 years old at the time. Our period of follow-up ranged from one to 28 years (average 14 years), similar to the series reported from New Zealand. ${ }^{4}$ Forty-four $(20 \%)$ of the 218 patients in that series underwent surgical treatment and the mean age at operation was 14.2 years, compared with 11.8 years in our series. Nine of the New Zealand patients underwent homograft aortic valve replacement as the primary operation, 
one had an exploratory procedure only, and 34 had aortic valvotomy. Among these 34, there were six late deaths, 10 had valve replacement four to 14 years after valvotomy and 18 remained well. Our 19 patients who required valve replacement after previous valvotomy did so rather earlier (at two to eight years). Hossack and his colleagues ${ }^{4}$ had much more stringent criteria for recommending surgery, and this may explain both the higher mean age at operation and the fact that proportionately fewer patients had surgery.

The indications we describe for proceeding to cardiac catheterisation and probable surgery have been progressively modified. Two-dimensional echocardiography now offers great potential in the management of this condition. Estimates of left ventricular wall thickness, cavity size, and ejection fraction by ultrasound examination at six-monthly intervals can now provide information on left ventricular function and indicate whether the obstruction is worsening.

The type of procedure performed at operation depends not only on the age of the patient but also on the morphology of the valvar or subvalvar obstruction. A subvalvar obstruction can be excised quite simply in some cases but in others the combination of fibrous and muscular tissue makes relief of the subvalvar obstruction difficult if not impossible. Further surgery may be required at a later date, as proved necessary in two of our patients. Supravalvar stenosis will require a patch in most instances. In infants and small children with valvar stenosis valvotomy is usually the method of choice, as the valve ring is too small to accommodate a valve prosthesis of adequate dimensions. Our youngest patient having valve replacement was 12 years. Occasionally in bicuspid valves in infants the valve tissue and cusps may be so thickened that commissurotomy is of very limited and short-term benefit. ${ }^{5}$ Dobell and his colleagues from Montreal ${ }^{5}$ reported 50 infants and children who underwent aortic commissurotomy, and found that a second operation was necessary in $33 \%$ within 10 years. Few would agree, however, with their conclusion that a gradient of $90 \mathrm{~mm} \mathrm{Hg}$ was required before operation was recommended. Sommerville et al reported the follow-up of 52 patients after open valvotomy. ${ }^{6}$ Their age at valvotomy ranged from 3 to 28 years. Twenty had had operations to replace the valve and 15 were awaiting one. They concluded that all would require reoperation within 20 years after valvotomy. In our experience seven out of 19 patients who had undergone commissurotomy required valve replacement two to eight years later because of evidence of increasingly severe obstruction.

The ideal prosthesis for valve replacement is not yet available, as each type has disadvantages as well as advantages. Our limited experience with xenograft porcine valves in four young patients was disappointing, as three had to be replaced within a few years because of calcification. Fiddler et $a^{7}$ had similar results, attributing the early appearance of calcification to the rapid turnover in calcium metabolism in children. Aortic homografts have been used with increasing success in children, ${ }^{8}$ but we have had no experience with homografts.

We would favour the Björk-Shiley mechanical prosthesis at present, although it has the obvious disadvantage of requiring long-term anticoagulation. This is difficult in children and even more so in young women who wish to embark on pregnancy. A 을 safe pregnancy with the birth of a normal child can be accomplished by careful supervision and adjustment of anticoagulant treatment. ${ }^{10}$

Congenital aortic stenosis in our experience is therefore not a benign condition throughout child- $\mathbb{\Phi}$ hood as surgical intervention was necessary in 43 $(33.6 \%)$ of our 128 patients before the age of 20 years. In addition, there was one sudden death in a boy of 5 years who had not had surgical treatment. We consider that to await the onset of symptoms before operation is recommended 4 is too rigid, and may unnecessarily delay effective treatment. Increasing left ventricular hypertrophy on the electrocardiogram and a gradient over $50 \mathrm{~mm} \mathrm{Hg}$ across the left ventricular outflow tract are important indications for operation. Surgical treatment does not eliminate the continuing need for antibiotic cover for dental extraction or operation in the mouth, nose, or throat.

We are indebted to our surgical colleagues, $\mathrm{Mr}$. T. M. Welsh and Mr. J. Pollok, who operated on the 46 patients in our study.

\section{References}

${ }^{1}$ Kiloh GA. Pure aortic stenosis. Br Heart $J$ 1950;12: 33-36.

${ }^{2}$ Campbell $M$. The natural history of congenital aortic ${ }^{\infty}$ stenosis. Br Heart J 1968;30:514-526.

${ }^{3}$ Nadas AS, Fyler DC. Paediatric cardiology, 3rd ed. WB Saunders 1972. 107-109.

4 Hossack KF, Neutze JM, Lowe JB, Barratt-Boyes BG. Congenital valvar aortic stenosis. Natural history and $T^{\top}$ assessment for operation. Br Heart $J$ 1980;43: 561-573.

5 Dobell ARC, Bloss RS, Gibbons JE, Collins GF. Con- $\frac{\Omega}{\overparen{ }}$ genital valvular aortic stenosis. Surgical management and long-term results. J Thorac Cardiovasc Surg 1981;81:916-920. 
6 Sommerville J, Presbitero P, Ross D. Open aortic valvotomy in the young: problems for the future. $\mathrm{Br}$ Heart J 1981;45:351 (proceedings of British Cardiological Society).

${ }^{7}$ Fiddler GI, Walker DR, Gerlis LM, Scott O. Calcified xenografts in children. Br Heart J 1981;45:352 (proceedings of British Cardiological Society).

${ }^{8}$ Fagan A, Radley-Smith R, Yacoub M. Aortic valve operations in children. $\mathrm{Br}$ Heart $\mathrm{J} 1981 ; 45: 618$ (proceedings of British Cardiological Society).

' Reid JM, Barclay RS. Pregnancy and mitral valve prosthesis. Br Med J 1971;i:326-7.

${ }^{10}$ O'Neill H, Blake S, McDonald S, Sugrue D. Management of patients with artificial valves during pregnancy. Br Heart J 1981;45:614 (proceedings of British Cardiological Society). 